\title{
Accumulation of "Small Dense" Low Density Lipoproteins (LDL) in a Homozygous Patient with Familial Defective Apolipoprotein B-100 Results from Heterogenous Interaction of LDL Subfractions with the LDL Receptor
}

\author{
Winfried März, * Manfred W. Baumstark, ${ }^{*}$ Hubert Scharnagl, * Viktor Ruzicka, * Sigune Buxbaum, * \\ Jürgen Herwig," Tilla Pohl," Andreas Russ, * Ludwig Schaaf," Aloys Berg," \\ Hans-Josef Böhles, "Klaus Henning Usadel," and Werner Gro $\beta^{\star}$ \\ ${ }^{*}$ Gustav Embden-Center of Biological Chemistry, Johann Wolfgang Goethe-University, W-60590, Frankfurt; ${ }^{\ddagger}$ Department of Sports \\ Medicine, Center of Internal Medicine, Albert Ludwigs-University, 79106 Freiburg; and ${ }^{\S}$ Center of Pediatrics and "Department of \\ Endocrinology, Center of Internal Medicine, Johann Wolfgang Goethe-University, W-60590 Frankfurt, Germany
}

\begin{abstract}
The interaction of LDL and LDL subfractions from a patient homozygous for familial defective apoB-100 (FDB) has been studied. His LDL cholesterol ranged from 2.65 to $3.34 \mathrm{~g} /$ liter. In cultured fibroblasts, binding, internalization, and degradation of the patient's LDL was diminished, but not completely abolished. The patient's apolipoprotein $\mathbf{E}$ concentration was low, and the amount of apolipoprotein $\mathbf{E}$ associated with LDL was not elevated over normal. LDL were separated into six subfractions: LDL-1 (1.019-1.031 kg/liter), LDL-2 (1.031$1.034 \mathrm{~kg} /$ liter), LDL-3 (1.034-1.037 kg/liter), LDL-4 (1.037-1.040 kg/liter), LDL-5 (1.040-1.044 kg/liter), and LDL-6 (> $1.044 \mathrm{~kg} /$ liter). LDL-5 and LDL-6 selectively accumulated in the patient's plasma. Concentrations of LDL-1 to 3 were normal. The LDL receptor-mediated uptake of LDL-1 and LDL-2 could not be distinguished from normal LDL. LDL3 and LDL-4 displayed reduced uptake; LDL-5 and LDL-6 were completely defective in binding. When apolipoprotein $\mathrm{E}$ containing particles were removed by immunoabsorption before preparing subfractions, LDL-3 and LDL-4, but not LDL-1 and LDL-2, retained some receptor binding activity. We conclude that in FDB, LDL-1 and LDL-2 contain sufficient apolipoprotein $\mathbf{E}$ to warrant normal cellular uptake. In LDL-3 and LDL-4, the defective apoB-100 itself displays some receptor binding; LDL-5 and LDL-6 are inable to interact with LDL receptors and accumulate in plasma. (J. Clin. Invest. 1993. 92:29222933.) Key words: hypercholesterolemia - familial defective apolipoprotein B-100 • LDL receptor $\bullet$ LDL-subfractions • atherosclerosis
\end{abstract}

\section{Introduction}

Apolipoprotein (apo) ${ }^{1}$ B-100 is a major constituent of VLDL, intermediate density lipoprotein (IDL), and LDL. The inter-

Address correspondence to Dr. Winfried März, Gustav EmbdenCenter of Biological Chemistry, Johann Wolfgang Goethe-University, University Hospital, Theodor Stern-Kai 7, 60590 Frankfurt/Main, Germany.

Received for publication 20 July 1992 and in revised form 5 August 1993.

1. Abbreviations used in this paper: apo, apolipoprotein; $\mathrm{C}$, cholesterol; FDB, familial defective apoB-100; FH, familial hypercholesterolemia; IDL, intermediate density lipoprotein.

J. Clin. Invest.

(c) The American Society for Clinical Investigation, Inc.

$0021-9738 / 93 / 12 / 2922 / 12 \$ 2.00$

Volume 92, December 1993, 2922-2933 action of apoB-100 with LDL receptors is responsible for the transfer of LDL cholesterol (LDL-C) from blood into the liver and most other cells in the body (1-4).

A mutation in codon 3500 of the apoB gene substituting glutamine for arginine has been shown to be associated with diminished LDL receptor binding. This disorder, which is also referred to as familial defective apoB-100 (FDB), is characterized by high plasma cholesterol and $\operatorname{LDL}$ levels $(5,6)$. FDB is transmitted in an autosomal codominant fashion. Heterozygous FDB has been estimated to occur in 1-3\% of hypercholesterolemic humans ( 7 ), thus being at least as frequent as classical familial hypercholesterolemia.

Homozygotes for the glutamine for arginine substitution have not yet been described in detail. The characterization of FDB-LDL had, therefore, to rely on LDL prepared from heterozygote mutation carriers. These studies have suggested that LDL in patients with FDB are essentially normal in regard to lipid composition, shape, and size (7). Since one LDL particle contains a single molecule of apoB, two LDL populations are present in heterozygotes. This has greatly confounded attempts to determine the actual receptor binding of FDB-LDL. Initial competition experiments using LDL from FDB heterozygotes, which represent a mixture of normal and mutant LDL particles, resulted in $\sim 30 \%$ binding compared with normal LDL (5). Later, Innerarity et al. (8) partially purified FDB-LDL by immunoaffinity chromatography with the mAb MB19, which binds one of two common apoB alleles with 11-fold higher affinity than the other. In that work, the defective LDL was estimated to possess only $3-5 \%$ of the normal binding activity.

Reports on the impact of FDB on cholesterol and LDL-C are also contradictory. Tybjaerg-Hansen et al. (9) found that the mean plasma cholesterol in 10 FDB heterozygotes (3.69 $\mathrm{g} /$ liter) was indistinguishable from that in heterozygous patients with familial hypercholesterolemia (FH). However, in an extensive study performed by Innerarity et al. (7) mean cholesterol in FDB subjects was $2.69 \mathrm{~g} /$ liter, in contrast to 3.60 $\mathrm{g} /$ liter in a large group of $\mathrm{FH}$ heterozygotes.

We have recently identified a 54-yr-old hypercholesterolemic patient who is homozygous for the glutamine for arginine mutation at position 3500 of apoB-100 (10). Surprisingly, hypercholesterolemia in this patient was moderate compared with homozygous familial hypercholesterolemia and to many reported FDB heterozygotes. This raises the question whether compensatory mechanisms alleviate the consequences of FDB. In this work, we show that in FDB the receptor interaction of buoyant LDL is normal due to the presence of apoE in these particles. In addition, we provide evidence that the glutamine for arginine substitution at position 3500 most profoundly alters the conformation of the apoB receptor binding domain 
when apolipoprotein B resides on particles at the lower and upper limits of the LDL density range (hydrated densities of 1.019-1.034 and 1.040-1.063 kg/liter). We conclude that these mechanisms distinguish FDB from FH and account for the mild hypercholesterolemia in homozygous FDB.

\section{Methods}

Case report. The FDB homozygous patient (F.B.) is the father of two heterozygotes (N.B. and Y.B.) who were identified by screening of pooled blood from hypercholesterolemic children at the Center for Pediatrics of the Frankfurt University Hospital. In earlier routine examinations, F.B. had persistent high total cholesterol concentrations. $8 \mathrm{yr}$ ago he had noted xanthelasmas on both eyelids. Total cholesterol ranged between 3.0 and $4.0 \mathrm{~g} /$ liter in repeated blood analyses. A lipidlowering drug had been prescribed after dietary efforts had failed, but the patient had not taken the drugs prescribed and was lost to follow up by his local physician.

F.B. is a 54-yr-old white male without serious symptoms of disease. He does not smoke and drinks little alcohol. The medical history indicates a single period of hospitalization for an apparent migraine headache $2 \mathrm{yr}$ previously. Apart from a recurring mild chest pain without radiation or major discomfort and the consistently high blood cholesterol that could not be influenced by diet, he has always been healthy. He had once taken lipid-lowering drugs but stopped taking them after symptoms of general discomfort appeared, which he attributed to the medication.

On physical examination the patient appeared well. The head was normal except for both upper eyelids, which revealed multiple xanthelasmas, $\sim 3 \mathrm{~mm}$ in diameter, and for a discrete arcus lipoides corneae.

Lungs, heart, and abdomen were normal. All peripheral pulses were palpable. The extremities were normal. There were no xanthomas of the tendons. Neurologic examination was negative.

Results of the routine laboratory examination were: glucose, 800 $\mathrm{mg} /$ liter; sodium, $142 \mathrm{mmol} /$ liter; potassium, $3.6 \mathrm{mmol} /$ liter; alkaline phosphatase, $97 \mathrm{U} /$ liter; ALAT, $25 \mathrm{U} /$ liter; ASAT, $16 \mathrm{U} /$ liter; $\gamma$-glutamyltransferase 34 , $\mathrm{U} /$ liter; leucocytes, $6,000 / \mathrm{mm}^{3}$; hemoglobin, $164 \mathrm{~g} /$ liter; hematocrit, $46.5 \%$. Mean corpuscular volume, hemoglobin concentration, and hemoglobin were all within normal range. Laboratory values for calcium, chloride, phosphate, iron, bilirubin, albumin, urea, creatinine, and uric acid were normal. Creatinine phosphokinase ( $35 \mathrm{U} /$ liter), lipase ( $55 \mathrm{U} /$ liter), and urine analysis were normal. The erythrocyte sedimentation rate was $2 / 4$. Thyroid-stimulating hormone levels, free T3, and free T4 were normal. An exercise electrocardiogram disclosed normal sinus rhythm and showed no sinus tachycardia abnormalities. A chest $\mathrm{x}$-ray was normal. Consistent with the slight increase in gamma-GT activity, ultrasonography of the abdomen revealed a fatty liver. Gallbladder, pancreas, spleen, kidneys, and thyroid were normal. There was no evidence for premature sclerosis of the aorta. The carotids and vertebral arteries appeared normal on Doppler sonography.

DNA preparation and oligonucleotides. Oligonucleotides were synthesized using the phosphoramidite chemistry on an DNA synthesizer (381A; Applied Biosystems, Inc., Foster City, CA) and purified on oligonucleotide purification cartridges (Applied Biosystems, Inc.). DNA was isolated from whole blood using "blood PCR" DNA isolation cartridges (Diagen $\mathrm{GmbH}$, Düsseldorf, Germany) according to the manufacturer's instructions.

Screening of pooled blood samples for FDB. Screening of pooled blood samples for FDB was carried out using a two-step amplification refractory mutation system (11). Individual blood samples contributing to positive pools were assayed for the presence of FDB using a modification (11) of the MspI restriction typing method described by Hansen et al. (12).

Sequencing of PCR-amplified DNA. Biotinylated primer R2A (5'CCTACTGTCTCTTCCTCCATGGAA-3') and primer R2B (5'TGGAAGGAACTGGGCTGACTT- $3^{\prime}$ ) corresponding to apoB
cDNA (13) nucleotides 10354-10377 and 10812-10832, respectively, were used to amplify a 479-bp fragment encompassing codon 3500 . The amplification reaction $(50 \mu \mathrm{l})$ contained $200 \mathrm{ng}$ genomic DNA, 20 pmol oligonucleotide primers, $62.5 \mathrm{mM} \mathrm{KCl}, 12.5 \mathrm{mM}$ Tris(hydroxymethyl)aminomethane (Tris)- $\mathrm{HCl}$ (pH 8.3), $2.125 \mathrm{mM} \mathrm{MgCl}, 50$ $\mu \mathrm{M}$ each of dATP, dCTP, dGTP, and dTTP, $10 \%$ (vol/vol) DMSO, $0.11 \%(\mathrm{vol} / \mathrm{vol})$ Tween-20, $0.11 \%$ (vol/vol) NP-40, and $2.5 \mathrm{U} \mathrm{Taq}$ polymerase (Perkin Elmer Cetus, Emeryville, CA). The reaction conditions were $95^{\circ} \mathrm{C}$ for $1 \mathrm{~min}, 60^{\circ} \mathrm{C}$ for $1 \mathrm{~min}$, and $72^{\circ} \mathrm{C}$ for $2 \mathrm{~min}$, for 30 cycles.

The biotinylated PCR products $(40 \mu l)$ were incubated with prewashed streptavidin-coated paramagnetic beads (Dynal, Oslo, Norway) and the biotin-modified single strand was isolated according to the method described by the manufacturer. Sequencing was performed using the dideoxynucleotide chain termination method (14) and the Sequenase 2.0 kit (United States Biochem. Corp., Cleveland, $\mathrm{OH}$ ). Reactions contained 1 pmol primer BCR (5'-GAATATATGCGTTGGAGTGTGGCTTCTCC-3'; positions 10654-10682) and $0.5 \mu \mathrm{l} \alpha$ [ ${ }^{32}$ P] ATP (DuPont de Nemour, Bad Homburg, Germany).

Lipoprotein and apolipoprotein analyses. Lipids were measured by enzymatic methods. VLDL $(d<1.0063 \mathrm{~kg} /$ liter $)$, IDL $(1.0063<d$ $<1.019 \mathrm{~kg} /$ liter $)$, and LDL $(1.019<d<1.065 \mathrm{~kg} /$ liter $)$ were isolated by preparative ultracentrifugation $(15,16)$. HDL cholesterol (HDLC) was determined after precipitation of apoB-containing lipoproteins (15). ApoA-I and apoB were measured by automated rate nephelometry (Array Protein System; Beckman Instrs., Inc., Fullerton, CA). ApoE phenotyping was performed by immunoblotting in immobilized $\mathrm{pH}$ gradients (17).

Enzyme immunoassay for apoE. Microplates were coated with 150 $\mu l$ polyclonal anti-apoE (from sheep; Daiichi Pure Chemicals, Tokyo, Japan) diluted 1:2,000 in $0.2 \mathrm{~mol} /$ liter carbonate buffer ( $\mathrm{pH} \mathrm{10.0),}$ blocked with $10 \mathrm{~g} /$ liter albumin (in carbonate buffer), and washed with $200 \mu \mathrm{lPBS}(0.14 \mathrm{~mol} /$ liter NaCl, $2.7 \mathrm{mmol} /$ liter $\mathrm{KCl}, 10 \mathrm{mmol} /$ liter $\mathrm{Na}_{2} \mathrm{HPO}_{4}, 1.5 \mathrm{mmol} /$ liter $\mathrm{KH}_{2} \mathrm{PO}_{4}, \mathrm{pH} 7.4$ ) containing $0.05 \%$ ( $\mathrm{vol} / \mathrm{vol}$ ) Tween 20 . Samples $(100 \mu \mathrm{l})$ were incubated for $3 \mathrm{~h}$. The plates were washed three times and then incubated for $2 \mathrm{~h}$ with a mouse anti-apoE mAb (1:10,000; Biogenesis, Bournemouth, England). Wells were washed, and incubated with peroxidase labeled anti-mouse IgG (1:750; Boehringer Mannheim Biochemicals, Indianapolis, IN). Color was developed with $o$-phenylenediamine $(9.25 \mathrm{mmol} /$ liter in 100 $\mathrm{mmol} /$ liter sodium citrate, $\mathrm{pH} 5.0)$ and $\mathrm{H}_{2} \mathrm{O}_{2}(1.8 \mathrm{mmol} /$ liter $)$ for 15-30 min. The reaction was stopped by adding $0.5 \mathrm{mmol} /$ liter $\mathrm{H}_{2} \mathrm{SO}_{4}$ and absorbance was read at $450 \mathrm{~nm}$ (Titertek MCC 340; Flow Laboratories, McClean, VA). Standard curves were obtained by running five dilutions of a frozen plasma pool that had been calibrated against purified apoE (18).

$L D L$ subfractions. Total LDL $(1.019<d<1.063 \mathrm{~kg} /$ liter $)$ were fractionated into six density classes by equilibrium density gradient centrifugation as described (19). Density ranges of the subfractions, as determined by precision refractometry (16) of blank gradients, were (in kg/liter): LDL-1, < 1.031; LDL-2, 1.031-1.034; LDL-3, 1.034 1.037; LDL-4, 1.037-1.040; LDL-5, 1.040-1.044; LDL-6, 1.044. All centrifugation steps were carried out at $18^{\circ} \mathrm{C}$ using partially filled polycarbonate bottles $(6 \mathrm{ml})$ in a 50Ti rotor (Beckman Instrs., Inc., Fullerton, CA). ApoB was measured by nephelometry (Behringwerke, Marburg, Germany), previously standardized on the basis of amino acid analysis in an LDL-3/LDL-4 pool (19).

Removal of apoE-containing particles from $L D L$. ApoE-containing particles were removed from LDL using immunoaffinity chromatography. Anti-apoE Ig from sheep was coupled to cyanogen bromide-activated Sepharose (Pharmacia Fine Chemicals, Piscataway, NJ) as described in the manufacturer's instructions. The immunoabsorbent was poured into a column (bed height, $58 \mathrm{~mm}$; diameter, $26 \mathrm{~mm}$ ) and equilibrated with column buffer containing $10 \mathrm{mmol} /$ liter Tris- $\mathrm{HCl}$ (pH 7.4), $0.15 \mathrm{~mol} /$ liter $\mathrm{NaCl}, 1 \mathrm{mmol} /$ liter EDTA $\cdot \mathrm{Na}_{2}$. LDL preparations were dialyzed against the same buffer, applied to the column, and allowed to equilibrate with the matrix at $4^{\circ} \mathrm{C}$ overnight. ApoE-free LDL were eluted with $0.1 \mathrm{~mol} /$ liter $\mathrm{NaHCO}_{3}(\mathrm{pH} \mathrm{8.0}), 0.5 \mathrm{~mol} /$ liter 
$\mathrm{NaCl}, 1 \mathrm{mmol} /$ liter EDTA $\cdot \mathrm{Na}_{2}$. The apoE-containing material was eluted with $1 \mathrm{~mol} /$ liter $\mathrm{CH}_{3} \mathrm{COOH}(\mathrm{pH} 2.7$ ), $0.5 \mathrm{~mol} /$ liter $\mathrm{NaCl}, 1$ $\mathrm{mmol} /$ liter EDTA $\cdot \mathrm{Na}_{2}$, and the absorbent was immediately washed with several volumes of column buffer.

Fast lipoprotein chromatography. $1 \mathrm{ml}$ plasma was loaded onto a 500 -mm column of Superose 6 (prep grade; Pharmacia Fine Chemicals) and eluted with $200 \mathrm{mmol} /$ liter $\mathrm{NaCl}, 100 \mathrm{mmol} /$ liter $\mathrm{Na}_{2} \mathrm{HPO}_{4}$ ( $\mathrm{pH} 7.4$ ) at a flow rate of $0.5 \mathrm{ml} \cdot \mathrm{min}^{-1}(20)$. The column eluate was fractionated and analyzed for cholesterol and apoE.

Binding, uptake, and degradation of ${ }^{125}$ I-labeled LDL (21). LDL were iodinated using $n$-bromosuccinimide as oxidizing agent (22). Monolayers of normal human skin fibroblasts were grown in 24-well polystyrene plates in RPMI 1640 supplemented with $10 \%$ ( $\mathrm{vol} / \mathrm{vol}$ ) FCS at $37^{\circ} \mathrm{C}$ in a $5 \% \mathrm{CO}_{2}$ atmosphere. Cells were used at $75 \%$ confluency. They were preincubated for $40 \mathrm{~h}$ in medium containing $10 \%$ ( vol/vol) human lipoprotein-deficient serum in order to upregulate LDL receptors.

Binding of ${ }^{125} I-L D L$. Cells and solutions were chilled to $4^{\circ} \mathrm{C}$ for 30 min and then incubated for $1 \mathrm{~h}$ with ${ }^{125} \mathrm{I}$-labeled LDL in $1 \mathrm{ml}$ RPMI 1640 containing $10 \mathrm{mM}$ Hepes and $10 \%$ lipoprotein-deficient serum. Cells were washed three times with $1 \mathrm{ml}$ ice-cold washing buffer A ( 150 $\mathrm{mM} \mathrm{NaCl}, 50 \mathrm{mM}$ Tris- $\mathrm{HCl}, 2 \mathrm{~g} /$ liter BSA, pH 7.4), incubated twice for $10 \mathrm{~min}$ with $1 \mathrm{ml}$ washing buffer $A$, and twice with $1 \mathrm{ml}$ of washing buffer B (as for buffer A, but without albumin). Cells were then dissolved in $1 \mathrm{ml} 0.3 \mathrm{M} \mathrm{NaOH}$ and the cell associated radioactivity was counted.

Uptake and degradation of ${ }^{125} I-L D L$. Cells were incubated for $4 \mathrm{~h}$ at $37^{\circ} \mathrm{C}$ with ${ }^{125} \mathrm{I}$-labeled LDL in RPMI 1640 containing $24 \mathrm{mM}$ bicarbonate (pH 7.4) and 10\% human lipoprotein-deficient serum. Cells were then washed three times with $1 \mathrm{ml}$ ice-cold washing buffer $\mathrm{A}$, incubated twice for $10 \mathrm{~min}$ with $1 \mathrm{ml}$ washing buffer $\mathrm{A}$, and twice with $1 \mathrm{ml}$ of washing buffer $B$. The amount of label associated with the cells (binding plus internalization) was determined after lysis in $0.3 \mathrm{M}$ $\mathrm{NaOH}$. Degradation of LDL was determined in the conditioned medium as described (21).

Binding of $L D L$ to $\mathrm{mAb} M B 47$. Binding of apoB-specific $\mathrm{mAb}$ MB47 to LDL was determined by means of a solid-phase competitive enzyme immunoassay. Microplates (Immuno Plates I; Nunc, Roskilde, Denmark) were coated with $150 \mu \mathrm{l}$ control LDL $(10 \mu \mathrm{g} / \mathrm{ml}$ protein in $0.2 \mathrm{~mol} /$ liter carbonate buffer, $\mathrm{pH} 10.0$ ), blocked with $10 \mathrm{~g} /$ liter BSA in carbonate buffer, and washed with $200 \mu$ PBS containing $0.05 \%$ Tween 20 .

LDL were desalted on PD-10 columns (Pharmacia Fine Chemicals) equilibrated with PBS containing EDTA $\cdot \mathrm{Na}_{2}(0.3 \mathrm{mmol} /$ liter $)$, assayed for protein, and adjusted to $10 \mathrm{~g}$ /liter BSA and $0.05 \%$ Tween 20. LDL were then preincubated overnight with MB47 hybridoma supernate diluted 1:4,000 in PBS containing $0.3 \mathrm{mmol} /$ liter EDTA, 10 $\mathrm{g} /$ liter BSA, and $0.05 \%$ Tween $20.100 \mu$ l of these mixtures was loaded into LDL-coated wells and incubated for $2 \mathrm{~h}$. Thereafter, the plates were washed three times and the amount of antibody bound to immobilized LDL was determined with peroxidase-conjugated anti-mouse IgG (Boehringer Mannheim Biochemicals), diluted 1:750 in PBSTween-BSA. Color was developed with $o$-phenylenediamine, and absorbances were read as described above.

\section{Results}

The FDB homozygous patient (F.B.) studied here belongs to a family identified by screening of pooled blood from hypercholesterolemic children. The pedigree of the patient's family is shown in Fig. 1. Clinical data of family members studied so far are summarized in Table I.

At the time of the first presentation (May 14, 1992) the patient was on a normal diet and was not taking any lipid-lowering drugs. The following lipoprotein and apo concentrations were observed (Fig. 2): cholesterol, $3.31 \mathrm{~g} /$ liter; triglycerides, $0.98 \mathrm{~g} /$ liter; VLDL-C, $0.13 \mathrm{~g} /$ liter; IDL-C, $0.11 \mathrm{~g} /$ liter;

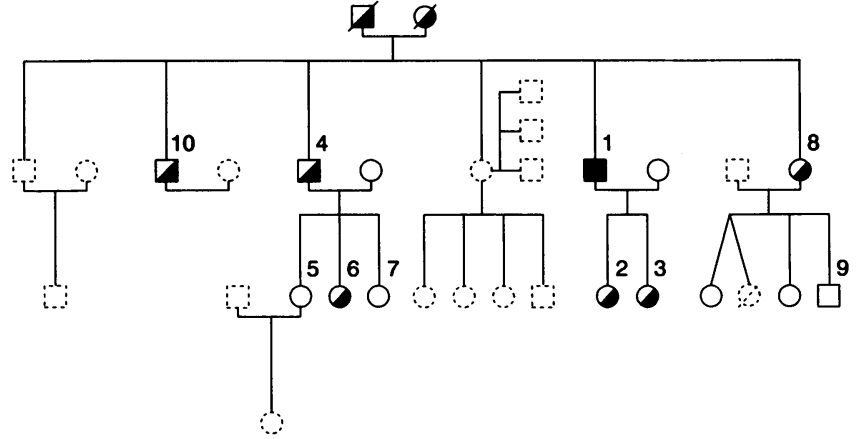

Figure 1. Pedigree of the B. family. The propositus (pedigree position 1, filled square) is homozygous for FDB. (Half-filled symbols) Pedigree members heterozygous for the mutation. Clinical information is provided in Table I. (Dotted symbols) Family members who have not been studied so far. (Circles) females; (squares) males; (oblique lines) deceased individuals.

LDL-C, 2.65 g/liter; HDL-C, 0.42 g/liter; apoA-I, $1.29 \mathrm{~g} /$ liter; apoB 2.45, g/liter; apoE, $35.6 \mathrm{mg} /$ liter; Lp(a), $11 \mathrm{mg} /$ liter; apoE phenotype, $3 / 3$. Clinical and laboratory findings were normal, with the exception that a slight increase in gamma-GT activity and a discrete fatty infiltration of the liver were present. Whether or not this liver affection was due to FDB homozygosity cannot be answered on the basis of the available clinical information. Most interesting, however, F.B. showed no evidence of atherosclerosis nor any significant cardiovascular complaints.

Although the patient was repeatedly given extensive dietary advice, his cholesterol and LDL-C concentrations increased to 3.90 and 3.34 g/liter, respectively (February 4, 1993; Fig. 2). By that time pravastatin therapy was started at $20 \mathrm{mg}$ daily. LDL-C and apoB fell by 18 and 23\%, respectively. By June 1, 1993, pravastatin was increased to $40 \mathrm{mg}$ daily. On July 8 , cholesterol and LDL-C were 2.90 and $2.31 \mathrm{~g} /$ liter, respectively (Fig. 2); compared with the pretreatment values, this corresponded to reductions in cholesterol and LDL-C by 26 and $31 \%$.

Restriction typing and direct sequencing. MspI restriction typing of in vitro amplified DNA suggested that F.B. was homozygous for the $G \rightarrow$ A substitution in codon 3500 of the apoB gene (Fig. 3). By direct sequencing of an in vitro amplified apoB gene fragment, we confirmed that F.B. was homozygous for $\mathrm{A}$ in position 10580 of the apoB cDNA, i.e., as for glutamine in position 3500 of apoB (Fig. 4).

Interaction of FDB-LDL with cultured cells. Cell surface binding, uptake, and degradation of FDB-LDL was studied in cultured human skin fibroblasts (Fig. 5). The binding, uptake, and degradation of FDB-LDL were clearly reduced, when compared with normal LDL. As expected, binding, uptake, and degradation of LDL from N.B. (FDB heterozygote) were intermediate between normal LDL and LDL from F.B. (FDB homozygote).

We also compared the ability of LDL from F.B., LDL from his heterozygous daughter N.B., and normal LDL to compete with labeled LDL for uptake in cultured fibroblasts. LDL from F.B. was largely ineffective as a competitor, whereas LDL from N.B. had about half the normal activity (Fig. 6). However, in several separate experiments, high concentrations of LDL from the homozygote (F.B.) were able to displace $\sim 20 \%$ of normal LDL from fibroblast receptors, regardless whether assessed as 
Table I. Clinical Data and Lipoproteins in the B. Family

\begin{tabular}{|c|c|c|c|c|c|c|c|c|c|c|c|c|c|}
\hline $\begin{array}{l}\text { Pedigree } \\
\text { position/ } \\
\text { initials }\end{array}$ & Age & Sex & Height & Weight & Cholesterol & Triglycerides & LDL-C & HDL-C & apoB & apoA-I & apoE & $\begin{array}{c}\text { apoE } \\
\text { phenotype }\end{array}$ & Lp(a) \\
\hline & $y r$ & & $\mathrm{~cm}$ & $k g$ & g/liter & g/liter & g/liter & g/liter & g/liter & g/liter & mg/liter & & U/liter \\
\hline 1 F.B. & 54 & $\mathbf{M}$ & 178 & 72 & 3.31 & 0.98 & $2.65^{\ddagger}$ & 0.42 & 2.45 & 1.29 & 35.6 & $3 / 3$ & 11 \\
\hline 2 N.B. & 17 & $\mathbf{F}$ & 170 & 56 & 2.87 & 0.61 & $2.10^{8}$ & 0.65 & 1.65 & 1.33 & 27.4 & $3 / 3$ & 180 \\
\hline 3 Y.B. & 14 & $\mathrm{~F}$ & 158 & 49 & 1.85 & 0.34 & $1.21^{8}$ & 0.57 & 1.02 & 1.32 & 31.9 & $3 / 3$ & 10 \\
\hline 4 W.B. & 51 & $\mathbf{M}$ & 163 & 78 & 3.31 & 0.65 & $2.73^{5}$ & 0.45 & 2.22 & 1.23 & 19.7 & $3 / 3$ & 1,160 \\
\hline 6 S.B. & 21 & $\mathbf{F}$ & 156 & 56 & 3.20 & 0.71 & $2.53^{8}$ & 0.52 & 2.17 & 1.37 & ND & $3 / 3$ & 855 \\
\hline 8 H.G. & 57 & $\mathbf{F}$ & 158 & 60 & 2.91 & 0.52 & $2.39^{8}$ & 0.41 & 1.83 & 1.17 & ND & $3 / 3$ & 701 \\
\hline 9 S.G. & 12 & $\mathbf{M}$ & 120 & 43 & 1.27 & 0.92 & $0.75^{5}$ & 0.33 & 0.71 & 0.98 & ND & $4 / 3$ & 7 \\
\hline 10 K.B. & 49 & $\mathbf{M}$ & 166 & 79 & 2.98 & 0.87 & $2.31^{8}$ & 0.49 & 1.77 & 1.40 & ND & $3 / 3$ & 1,080 \\
\hline
\end{tabular}

ND, not determined. * Multiply by 0.54 to convert U/liter into $\mathrm{mg} /$ liter (57). ${ }^{\ddagger}$ Preparative ultracentrifugation. VLDL-C and IDL-C were 0.13 and $0.11 \mathrm{~g} /$ liter. ${ }^{5}$ Calculated according to Friedewald et al. (58).

binding, uptake, or degradation. As shown in Fig. 6, the displacement curves produced by LDL from the homozygote (F.B.) appeared to contain two different slopes. Up to $5 \mathrm{mg} /$ liter LDL protein, the slope was similar to that of normal LDL. Above this threshold, the displacement curve paralleled the abscissa. The shapes of the displacement curves were reproducible in two experiments.

Distribution of $L D L$ subfractions. Studies on the distribution of LDL subfractions showed that the increase in LDL in the homozygote patient was attributable to LDL particles with densities $>1.037 \mathrm{~kg} /$ liter (LDL-4-LDL-6, cf. Fig. 7 and Table II). In contrast, the concentrations of apoB-containing particles in the less dense LDL subfractions (LDL-1-LDL-3), in

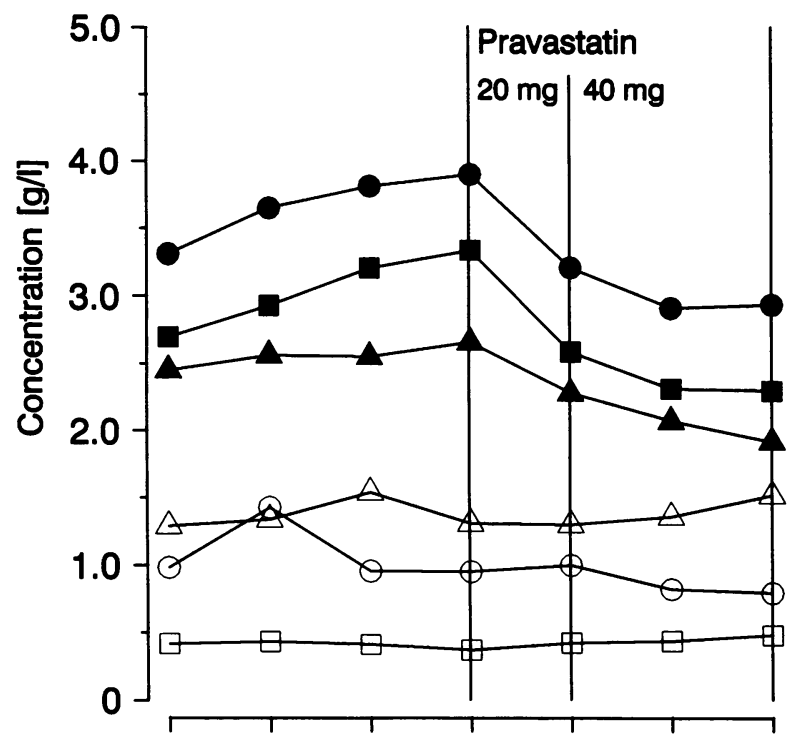

May 14, 92 Oct 9,92 June 1,93 July 8,93 June 12, 92 Feb 4, 93 June 16, 93

Figure 2. Lipid and lipoprotein concentrations in the FDB homozygous patient F.B. from May 1992 to July 1993. Cholesterol (filled circles), LDL-C (filled squares), apoB (filled triangles), triglycerides (open circles), HDL-C (open squares), apoA-I (open triangles). Pravastatin was given at $20 \mathrm{mg}$ daily by February 4, 1993 and at $40 \mathrm{mg}$ daily by June 1, 1993.
IDL, and in VLDL were completely normal. Essentially, lipid compositions and calculated particle diameters of LDL subfractions did not differ between normal and FDB-LDL (Table III). The only exception from this was that the cholesteryl ester content in VLDL and IDL from the FDB homozygote was increased.

Distribution of apoE among plasma lipoproteins. In an attempt to explain the unexpectedly low cholesterol and LDL-C concentrations in the FDB homozygote (F.B.), we investigated the possibility that the distribution of apoE among plasma lipoproteins was altered. In normal plasma, only trace amounts of apoE are associated with LDL. However, if FDB-LDL had an abnormally high apoE content, the uptake of LDL via apoE could be normal or even enhanced despite the presence of defective apoB-100. We determined the distribution of apoE

\section{8}

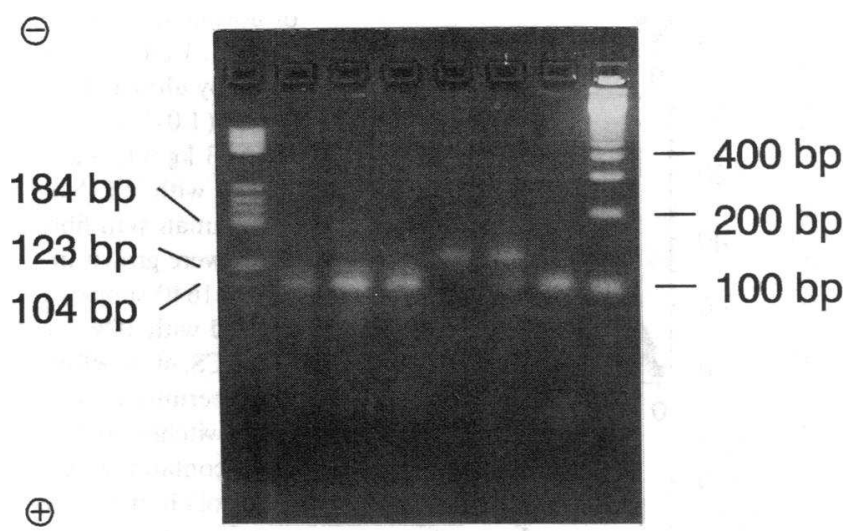

Figure 3. Typing of in vitro amplified DNA with MspI. A slight modification (8) of the method described by Tybjaerg-Hansen et al. (9) was used. In this method, a cleavage site for MspI is introduced into the normal, but not into the mutant apoB allele during PCR amplification. After MspI digestion, the normal allele gives a band of $104 \mathrm{bp}$ and the mutant a band of $133 \mathrm{bp}$. Lanes 1 and 8 contain DNA size standards; lanes 2-4 and lane 7 contain FDB-negative DNA. Digests from F.B. and from his daughter N.B. are in lanes 5 and 6 , respectively. In lane 5, the 104-bp band is completely absent, suggesting that F.B. is homozygous for the $A$ for $G$ transition replacing arginine by glutamine in position 3500 of apoB-100. 


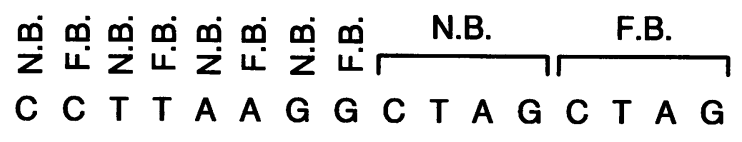

Ser 3496

Lys

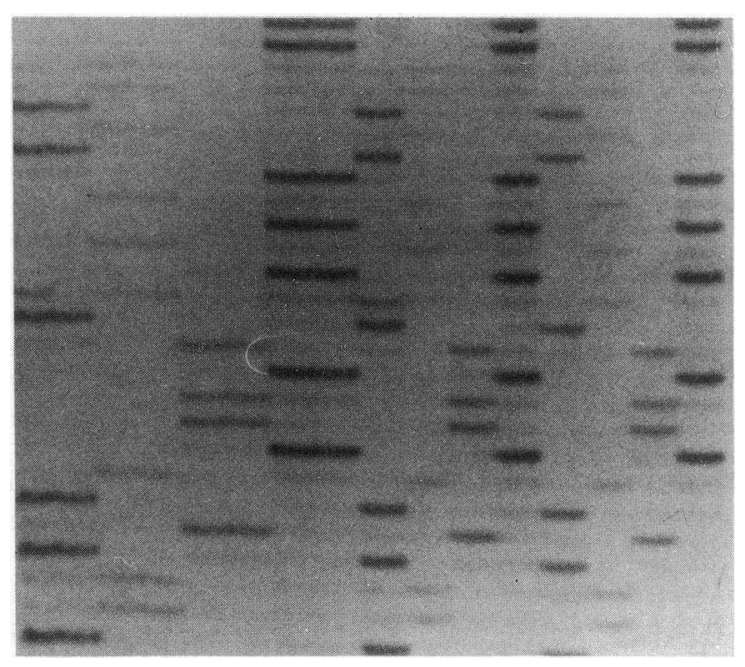

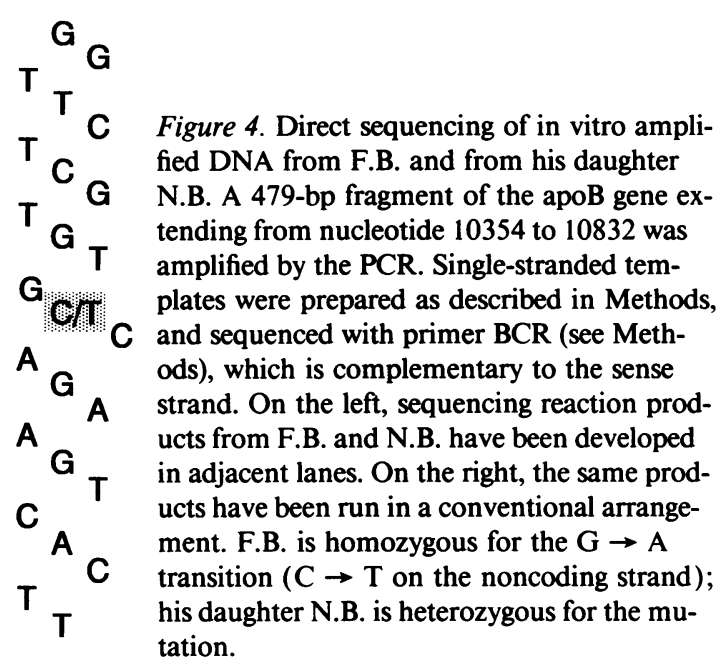

among lipoprotein classes. When lipoprotein fractions were prepared by ultracentrifugation, we found the following: in both VLDL and IDL from the FDB homozygote (F.B.) and from normal individuals, the apoE/apoB molar ratios exceeded unity ( Table III). In normal LDL, the apoE/apoB ratio was 1:5, compared with 1:8 in LDL from the FDB homozygote
(F.B.). The apoE content of LDL from the homozygote (F.B.) was thus even lower than normal. This was also true for his LDL subfractions (Tables II and III). The relative distribution of apoE among LDL subfractions was very similar in the FDB homozygote (F.B.) and in the healthy individuals studied. LDL-1 and LDL-2 had the highest apoE content, and LDL-4

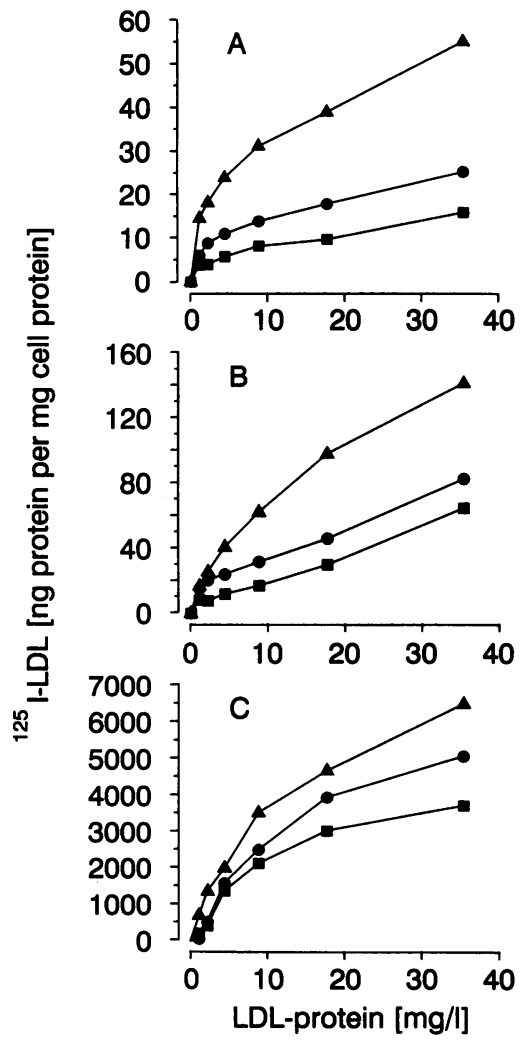
nonspecific binding, uptake, and degradation measured in the presence of 50-fold excess of unlabeled LDL.

Figure 5. Binding, uptake, and degradation of LDL from F.B. (FDB homozygote, squares), from his daughter N.B. (FDB heterozygote, circles), and from a pool of normal donors (triangles). LDL were prepared by ultracentrifugation $(1.019<d$ $<1.063 \mathrm{~kg} /$ liter) and labeled with ${ }^{125} \mathrm{I}$. Normal human skin fibroblasts were grown in RPMI 1640 supplemented with $10 \%$ (vol/ vol) FCS. $40 \mathrm{~h}$ before the experiment, they were switched to medium containing $10 \%$ (vol/vol) human lipoprotein-deficient serum. Cells then received ${ }^{125}$ I-labeled LDL at the indicated concentrations. Binding $(A)$, uptake $(B)$, and degradation $(C)$ were determined as described in Methods. Each data

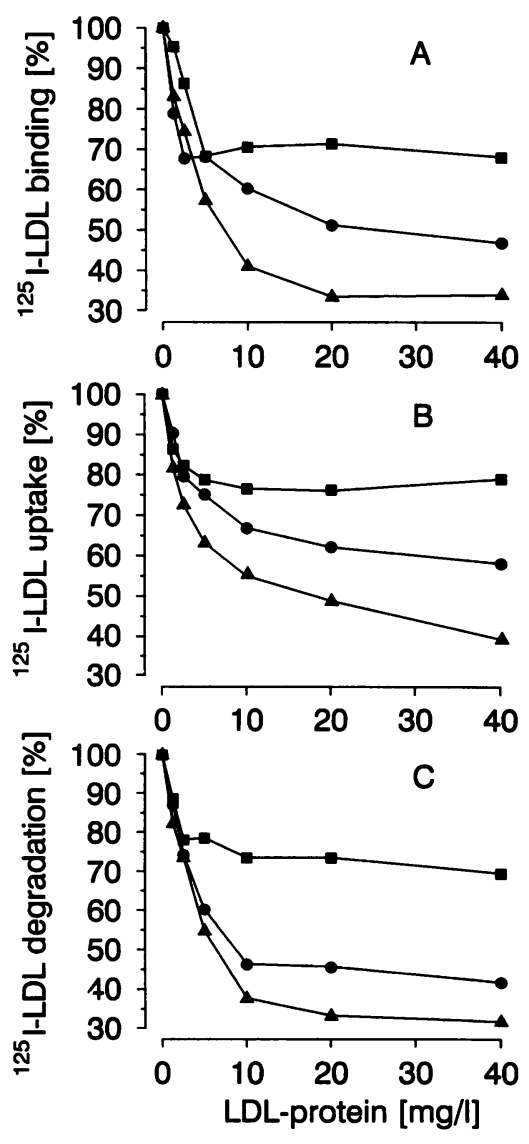

Figure 6. Competition for ${ }^{125}$ I-labeled LDL

binding, uptake, and degradation by LDL from F.B. (FDB homozygote, squares), from his daughter N.B. (FDB heterozygote, circles), and from a pool of normal donors (triangles). After preincubation (40 h) in medium containing $10 \%$ ( vol/vol) human lipoprotein-deficient serum, cells received $7.5 \mu \mathrm{g} / \mathrm{ml}$ ${ }^{125}$ I-LDL-protein and unlabeled competitor at the indicated concentrations. Binding $(A)$, uptake $(B)$, and degradation $(C)$ were determined as described in Methods. Each data point represents the average value from triplicates. LDL from F.B. (FDB homozygote) were completely ineffective as competitors, whereas LDL from his heterozygous daughter N.B. had about half the normal activity. 


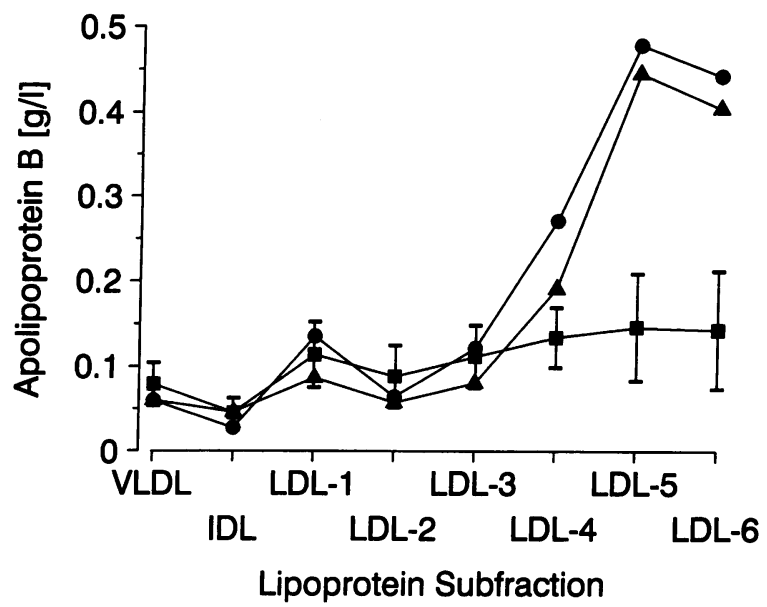

Figure 7. Density distribution of apoB-containing particles in a FDB homozygous patient (F.B.), compared with the distribution in normolipidemic individuals. Two independent samples from F.B. were analyzed (circles and triangles). The squares and the error bars (means \pm SD) show the lipoprotein distribution in normal individuals ( $n=55$; total cholesterol, $2.09 \pm 0.25 \mathrm{~g} /$ liter; triglycerides, $1.21 \pm 0.27$ $\mathrm{g} /$ liter).

and LDL-5 had the lowest (Table III). On average, one out of three LDL-1 particles contained an apoE molecule, in the FDB homozygote as well as in normal LDL.

It is well documented that apoE dissociates from the surface of apoB-containing particles during prolonged ultracentrifugation (23-26). Therefore, we also used gel filtration to assay the distribution of apoE in plasma (Fig. 8). In normal fasting plasma, apoE eluted in two major peaks. The first corresponded to particles of intermediate size between VLDL and LDL, and the second one appeared in the leading portion of the
HDL peak. Consistent with the low total apoE level in the plasma of the FDB homozygote, low concentrations of apoE were found in the column fractions prepared from his plasma. Unlike in normal plasma, in the FDB homozygote $>50 \%$ of apoE were found in the VLDL/IDL peak. The two apoE peaks occurred at normal retention times and, in absolute terms, the amount of apoE associated with the VLDL/IDL peak was not higher than in normal subjects. There was no evidence that FDB-LDL contained more apoE than normal LDL (Fig. 8).

Interaction of LDL subfractions with fibroblasts. Since the lipid and apolipoprotein composition of LDL and LDL subfractions were indistinguishable between homozygous FDB and normal individuals, other factors had to be responsible for the relatively low LDL concentration in the FDB homozygote. We therefore examined whether the interaction with LDL receptors differed between FDB-LDL subfractions. LDL subfractions were used as unlabeled competitors in assays for uptake and degradation of labeled LDL. Cellular degradation studies are shown in Fig. 9. Significant differences were found between LDL subfractions from FDB patients, regardless whether subfractions from N.B. (FDB heterozygote) or from F.B. (FDB homozygote) were studied. In comparison with LDL from healthy individuals, LDL-1 and LDL-2 behaved indistinguishably. LDL-3 and LDL-4 displayed decreased, but still detectable, receptor binding activity. LDL-5 and LDL-6 were completely ineffective in competing with normal LDL. Total LDL (1.019-1.063 kg/liter) from the FDB homozygote behaved as predicted for a mixture of the subfractions: the ability to compete with normal LDL for uptake in fibroblasts was markedly reduced, but not completely abolished.

To answer the question whether the small amounts of apoE present in buoyant LDL had caused these differences in receptor recognition, we removed apoE-containing particles from F.B.'s LDL by immunoabsorption before preparing LDL sub-

Table II. ApoB-containing Lipoproteins in a Homozygous Patient with FDB and in Normal Individuals

\begin{tabular}{|c|c|c|c|c|c|c|c|}
\hline & & $\begin{array}{l}\text { Unesterified } \\
\text { cholesterol }\end{array}$ & $\begin{array}{l}\text { Esterified } \\
\text { cholesterol }\end{array}$ & Triglycerides & Phospholipids & apoB & $\mathrm{apoE}^{*}$ \\
\hline \multirow[t]{2}{*}{ VLDL } & F.B. & $85.7 \pm 0.7$ & $196.0 \pm 17.4$ & $859.2 \pm 187.5$ & $240.3 \pm 22.7$ & $59.7 \pm 0.2$ & $15.43 \pm 6.32$ \\
\hline & Normals & $87.3 \pm 30.9$ & $196.1 \pm 67.2$ & $789.8 \pm 246.8$ & $288.0 \pm 90.3$ & $78.8 \pm 25.3$ & $25.61 \pm 7.96$ \\
\hline \multirow[t]{2}{*}{ IDL } & F.B. & $28.3 \pm 7.3$ & $123.8 \pm 42.6$ & $87.2 \pm 5.5$ & $70.5 \pm 16.5$ & $36.6 \pm 9.1$ & $12.32 \pm 5.97$ \\
\hline & Normals & $27.2 \pm 11.6$ & $109.2 \pm 49.1$ & $91.5 \pm 44.4$ & $83.2 \pm 36.5$ & $45.0 \pm 17.4$ & $7.34 \pm 4.59$ \\
\hline \multirow[t]{2}{*}{ LDL (total) } & F.B. & $643.5 \pm 22.5$ & $3,027.4 \pm 115.9$ & $203.5 \pm 17.5$ & $1,262.0 \pm 12.0$ & $1,606.2 \pm 235.9$ & $13.2 \pm 6.53$ \\
\hline & Normals & $285.2 \pm 54.0$ & $1,460.0 \pm 249.9$ & $166.9 \pm 46.6$ & $808.0 \pm 186.0$ & $705.1 \pm 140.3$ & $8.80 \pm 5.38$ \\
\hline \multirow[t]{2}{*}{ LDL-1 } & F.B. & $67.2 \pm 6.2$ & $325.3 \pm 41.7$ & $34.4 \pm 0.1$ & $152.5 \pm 14.6$ & $110.7 \pm 24.5$ & $2.16 \pm 0.72$ \\
\hline & Normals & $57.1 \pm 22.4$ & $260.0 \pm 90.1$ & $41.4 \pm 16.5$ & $155.8 \pm 62.6$ & $113.6 \pm 38.5$ & $2.96 \pm 1.66$ \\
\hline \multirow[t]{2}{*}{ LDL-2 } & F.B. & $30.9 \pm 1.6$ & $150.5 \pm 5.5$ & $13.0 \pm 1.0$ & $70.9 \pm 2.0$ & $60.5 \pm 3.5$ & $0.27 \pm 0.10$ \\
\hline & Normals & $40.2 \pm 20.4$ & $194.0 \pm 87.3$ & $21.4 \pm 8.7$ & $111.2 \pm 55.2$ & $88.0 \pm 36.6$ & $0.48 \pm 0.28$ \\
\hline \multirow[t]{2}{*}{ LDL-3 } & F.B. & $49.9 \pm 5.6$ & $237.4 \pm 24.7$ & $16.6 \pm 0.1$ & $109.2 \pm 12.7$ & $100.9 \pm 20.6$ & $0.24 \pm 0.05$ \\
\hline & Normals & $46.6 \pm 17.4$ & $233.4 \pm 79.1$ & $22.1 \pm 8.5$ & $130.3 \pm 49.1$ & $111.4 \pm 36.8$ & $0.28 \pm 0.16$ \\
\hline \multirow[t]{2}{*}{ LDL-4 } & F.B. & $119.8 \pm 13.4$ & $554.6 \pm 45.6$ & $33.5 \pm 2.5$ & $235.7 \pm 10.5$ & $231.1 \pm 40.2$ & $0.28 \pm 0.09$ \\
\hline & Normals & $51.2 \pm 12.8$ & $267.7 \pm 67.7$ & $23.6 \pm 7.8$ & $146.3 \pm 42.2$ & $134.0 \pm 35.2$ & $0.29 \pm 0.16$ \\
\hline \multirow[t]{2}{*}{ LDL-5 } & F.B. & $197.4 \pm 3.2$ & $985.7 \pm 8.5$ & $53.6 \pm 8.9$ & $439.8 \pm 1.9$ & $462.5 \pm 16.6$ & $0.31 \pm 0.15$ \\
\hline & Normals & $46.2 \pm 18.9$ & $268.4 \pm 114.6$ & $23.1 \pm 10.3$ & $141.6 \pm 59.0$ & $146.0 \pm 63.0$ & $0.35 \pm 0.13$ \\
\hline \multirow[t]{2}{*}{ LDL-6 } & F.B. & $155.0 \pm 1.2$ & $813.4 \pm 13.9$ & $49.7 \pm 7.2$ & $309.3 \pm 2.6$ & $424.3 \pm 19.1$ & $1.11 \pm 0.42$ \\
\hline & Normals & $40.7 \pm 17.5$ & $241.9 \pm 119.7$ & $27.0 \pm 11.5$ & $128.6 \pm 56.3$ & $143.0 \pm 69.3$ & $2.65 \pm 0.50$ \\
\hline
\end{tabular}

Absolute concentrations (mg/liter). Entries contain means \pm SD of two independent blood samples from F.B. and means \pm SD from $n=55$ normal individuals. * Data for normals are means from four individuals. 
Table III. Composition of apoB-containing Lipoproteins in a Homozygous Patient with FDB and in Normal Individuals

\begin{tabular}{|c|c|c|c|c|c|c|c|}
\hline & & $\begin{array}{l}\text { Unesterified } \\
\text { cholesterol }\end{array}$ & $\begin{array}{l}\text { Esterified } \\
\text { cholesterol }\end{array}$ & Triglycerides & Phospholipids & $\begin{array}{l}\text { Particle } \\
\text { radius }\end{array}$ & $\begin{array}{l}\text { apoE/apoB } \\
\text { molar ratio* }\end{array}$ \\
\hline & & & & & & $n m$ & \\
\hline \multirow[t]{2}{*}{ VLDL } & F.B. & $1,904 \pm 23$ & $2,591 \pm 219$ & $8,462 \pm 1,880$ & $2,668 \pm 263$ & $17.21 \pm 0.83$ & $4 / 1$ \\
\hline & Normals & $1,473 \pm 269$ & $1,990 \pm 439$ & $6,078 \pm 1,509$ & $2,484 \pm 560$ & $15.74 \pm 1.03$ & $5 / 1$ \\
\hline \multirow[t]{2}{*}{ IDL } & F.B. & $1,025 \pm 11$ & $2,603 \pm 270$ & $1,515 \pm 466$ & $1,281 \pm 21$ & $12.47 \pm 0.24$ & $5 / 1$ \\
\hline & Normals & $808 \pm 149$ & $1,914 \pm 394$ & $1,235 \pm 437$ & $1,232 \pm 252$ & $11.67 \pm 0.72$ & $3 / 1$ \\
\hline \multirow[t]{2}{*}{ LDL (total) } & F.B. & $540 \pm 61$ & $1,511 \pm 165$ & $77 \pm 18$ & $531 \pm 73$ & $9.30 \pm 0.31$ & $1 / 8$ \\
\hline & Normals & $544 \pm 88$ & $1,653 \pm 198$ & $141 \pm 36$ & $763 \pm 114$ & $9.78 \pm 0.32$ & $1 / 5$ \\
\hline \multirow[t]{2}{*}{ LDL-1 } & F.B. & $829 \pm 110$ & $2,369 \pm 227$ & $192 \pm 43$ & $939 \pm 120$ & $10.74 \pm 0.37$ & $1 / 3$ \\
\hline & Normals & $661 \pm 77$ & $1,813 \pm 217$ & $222 \pm 67$ & $900 \pm 141$ & $10.22 \pm 0.35$ & $1 / 3$ \\
\hline \multirow[t]{2}{*}{ LDL-2 } & F.B. & $678 \pm 3$ & $1,966 \pm 43$ & $127 \pm 17$ & $778 \pm 24$ & $10.13 \pm 0.08$ & $1 / 14$ \\
\hline & Normals & $592 \pm 80$ & $1,735 \pm 211$ & $152 \pm 49$ & $825 \pm 133$ & $9.96 \pm 0.37$ & $1 / 12$ \\
\hline \multirow[t]{2}{*}{ LDL-3 } & F.B. & $669 \pm 63$ & $1,896 \pm 195$ & $101 \pm 20$ & $730 \pm 66$ & $9.98 \pm 0.29$ & $1 / 27$ \\
\hline & Normals & $554 \pm 86$ & $1,669 \pm 231$ & $121 \pm 36$ & $777 \pm 137$ & $9.79 \pm 0.43$ & $1 / 26$ \\
\hline \multirow[t]{2}{*}{ LDL-4 } & F.B. & $695 \pm 44$ & $1,925 \pm 179$ & $89 \pm 22$ & $691 \pm 90$ & $9.96 \pm 0.30$ & $1 / 54$ \\
\hline & Normals & $514 \pm 70$ & $1,595 \pm 181$ & $105 \pm 29$ & $730 \pm 122$ & $9.63 \pm 0.37$ & $1 / 30$ \\
\hline \multirow[t]{2}{*}{ LDL-5 } & F.B. & $567 \pm 30$ & $1,683 \pm 46$ & $68 \pm 14$ & $630 \pm 25$ & $9.59 \pm 0.11$ & $1 / 97$ \\
\hline & Normals & $437 \pm 94$ & $1,478 \pm 216$ & $96 \pm 26$ & $662 \pm 122$ & $9.38 \pm 0.43$ & $1 / 27$ \\
\hline \multirow[t]{2}{*}{ LDL-6 } & F.B. & $485 \pm 18$ & $1,517 \pm 94$ & $69 \pm 13$ & $484 \pm 26$ & $9.21 \pm 0.16$ & $1 / 25$ \\
\hline & Normals & $391 \pm 64$ & $1,350 \pm 173$ & $117 \pm 28$ & $620 \pm 115$ & $9.21 \pm 0.36$ & $1 / 3$ \\
\hline
\end{tabular}

Entries are numbers of molecules per lipoprotein particle. The radii were calculated according to Baumstark et al. (19). Means \pm SD of two independent blood samples from F.B. and from $n=55$ normal individuals are reported. ${ }^{*}$ Calculated assuming molecular weights of 513,000 and 35,000 for apoB and apoE, respectively. Data for normals are means from four individuals.

fractions. Immunoabsorption reduced the apoE content of LDL by $\sim 95 \%$. As shown in Fig. 9, apoE depletion almost completely abolished binding of LDL-1 and LDL-2 from the homozygote (F.B.) to LDL receptors. In contrast, after re-
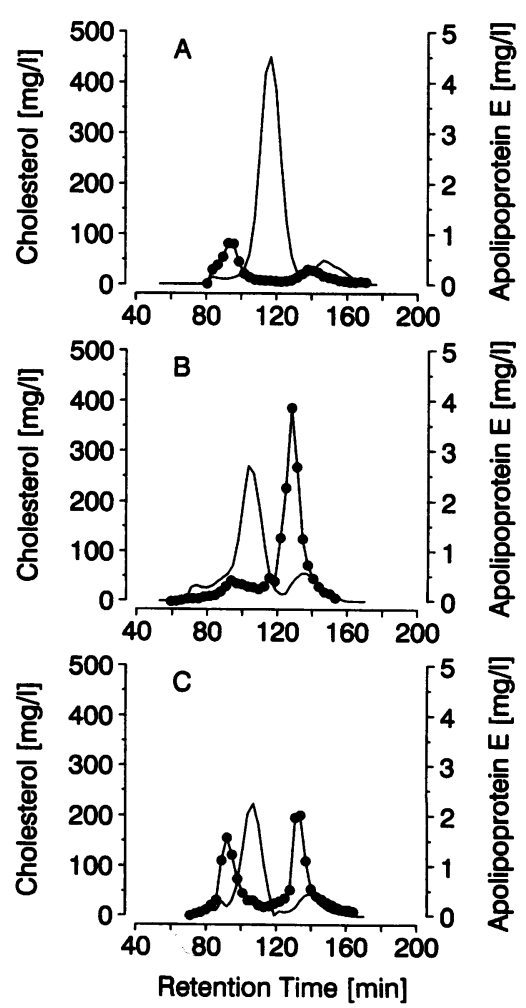

Figure 8. Size distribution of apoE-containing lipoproteins. Plasma (1 $\mathrm{ml}$ ) was separated on a Superose 6 prep grade column $(500 \mathrm{~mm}$ in length and $16 \mathrm{~mm}$ in diameter). Fractions were analyzed for cholesterol (enzymatic method, solid lines) and apoE (enzyme immunoassay, circles $).(A)$ Plasma from F.B. (FDB homozygote); $(B)$ plasma from N.B. (FDB heterozygote); $(C)$ plasma from a normolipidemic individual (plasma apoE concentration, $56 \mathrm{mg}$ /liter). moval of apoE-containing particles, homozygous LDL-3 and LDL-4 still displayed considerable receptor binding activity, whereas LDL-5 and LDL-6 had virtually none, as before immunoabsorption. We deduce from these data that apoE was responsible for the "normal" receptor binding of LDL-1 and LDL-2 from the FDB homozygote (F.B.). However, the residual receptor binding of LDL-3 and LDL-4 was not explained by this.

When we analyzed apoE-depleted LDL subfractions from pooled normal plasma for their ability to displace labeled LDL from cellular uptake, only slight differences were observed (data not presented graphically). The concentrations of LDL protein required for $50 \%$ inhibition of ${ }^{125} \mathrm{I}-\mathrm{LDL}$ degradation were $\sim 3 \mathrm{mg} /$ liter for LDL-3 and LDL-4. For LDL-1, LDL-5, and LDL-6, we obtained $50 \%$ inhibition at $4 \mathrm{mg} /$ liter protein; LDL-2 displayed intermediate receptor affinity, i.e., $50 \%$ inhibition, at $3.5 \mathrm{mg} /$ liter.

In all the above-mentioned experiments, identical results were obtained when cellular uptake was determined instead of degradation.

Binding of $F D B-L D L$ to $M A b M B 47$. Using a competitive enzyme immunoassay, we determined the binding of $\mathrm{mAb}$ MB47 to LDL from the FDB homozygote F.B. in comparison with LDL from his heterozygous daughter N.B. and with pooled LDL from healthy donors. As shown in Fig. 10, LDL from normal individuals had the lowest affinity for MB47. LDL from both the homozygote F.B. and the heterozygote N.B. displayed enhanced binding of MB47. The difference between LDL from the homozygote (F.B.) and from the heterozygote (N.B.) was small, indicating that in heterozygous FDB abnormal LDL predominates.

To elucidate whether apart from the presence of apoE in LDL-1 and LDL-2 another structural correlate accounted for 


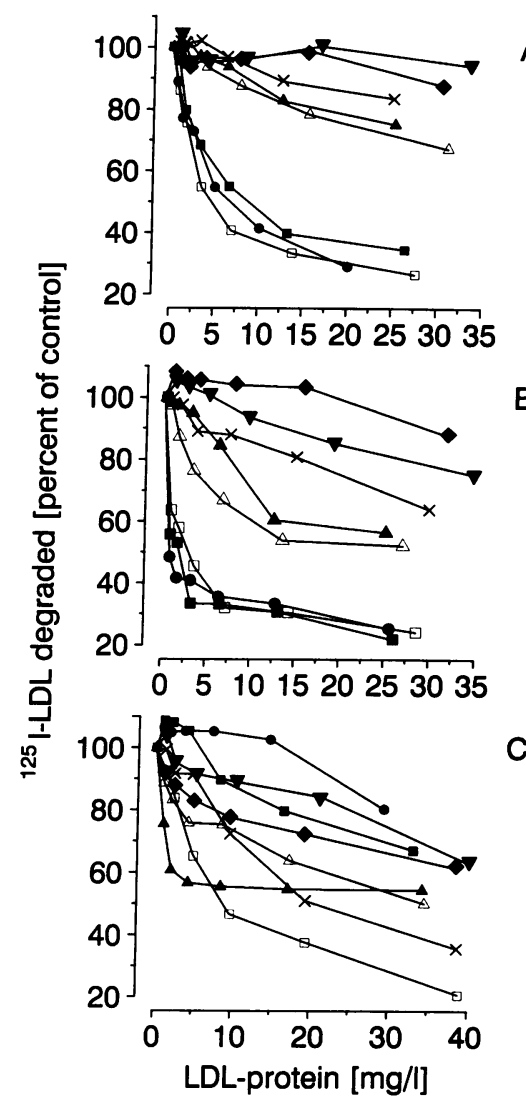

Figure 9. Competition

for ${ }^{125}$ I-labeled LDL uptake and degradation by LDL subfractions LDL-1 to LDL-6. Human skin fibroblasts were preincubated in medium containing $10 \%$ (vol/vol) human lipoprotein-deficient serum. Cells then re-

B ceived $7.5 \mu \mathrm{g} / \mathrm{ml}^{125} \mathrm{I}$ LDL and unlabeled LDL subfractions at the indicated concentrations. After $4 \mathrm{~h}$ of incubation at $37^{\circ} \mathrm{C}$ the amounts of LDL degraded were determined as described in Methods. ( $A$ ) LDL subfrac-

C tions from F.B. (FDB homozygote); (B) LDL subfractions from N.B. (FDB heterozygote) $(C)$ LDL subfractions from F.B. (FDB homozygote) after absorption of apoE-containing lipoproteins. Each data point represents the average value from trip-

licates. Data are adjusted for LDL degradation in the absence of cells. (Open squares) Pooled normal LDL; (open triangles) total LDL from F.B. $(A$ and $C$ ) or N.B. (B); (filled circles) LDL-1; (filled squares) LDL-2; (filled triangles) LDL-3; (asterisks) LDL-4; (solid rhomboids) LDL-5; (inverted triangles) LDL-6.

the different recognition of LDL subfractions by LDL receptors, we studied the interaction of MB47 with LDL subfractions. Results are shown in Fig. 10. The binding of MB47 to LDL subfractions decreased in the following order: LDL-5 $>$ LDL-6 > LDL-4 > LDL-3 > LDL-2 > LDL-1. Subfractions with the lowest LDL receptor binding (LDL-5 and LDL-6) had the highest affinities for MB47. LDL-1 and LDL-2, which were completely deficient in LDL receptor binding when depleted of apoE, had the lowest affinities for MB47.

\section{Discussion}

The best understood genetic abnormality of lipoprotein metabolism is FH. In FH, LDL clearance is diminished due to defective LDL receptors (4). In FDB, LDL clearance is reduced because LDL are defective in binding to $\operatorname{LDL}$ receptors $(5,6)$. We have identified a case of homozygous FDB (10). Homozygosity has been established by restriction typing and direct sequencing of in vitro amplified DNA. By analogy to $\mathrm{FH}$, the expected consequence of FDB homozygosity would be overt LDL accumulation due to abrogated receptor binding. However, even though our patient was homozygous, his cholesterol and LDL concentrations were far lower than in FH homozygotes and in many reported FDB heterozygotes.

Literature data on the expressivity of the FDB mutation are conflicting. Mainly, they rest on studies in FDB heterozygotes.

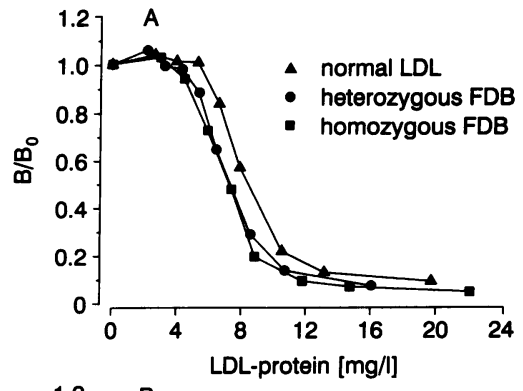

Figure 10. Binding of the mAb MB47 to FDB-LDL and FDBLDL subfractions determined with a solid phase enzyme immunoassay. Microwell plates were coated with normal LDL. Competitor LDL were incubated with MB47, and the amount of MB47 bound to the solid phase was measured using a peroxidase-labeled antimouse antibody. $B / B_{0}$ is the ratio of antibody bound to the solid phase in the presence of competitor LDL divided by the amount of antibody bound in the absence of competitor LDL. $(A)$

LDL (1.019-1.063 kg/liter) from F.B. (FDB homozygote, squares), from his daughter N.B. (FDB heterozygote, circles), and from a pool of healthy individuals (triangles). ( $B$ ) LDL subfractions from F.B. (FDB homozygote); (circles) LDL-1; (squares) LDL-2; (triangles) LDL-3; (asterisks) LDL-4; (rhomboids) LDL-5; (inverted triangles) LDL-6. Each data point represents the mean of triplicate $(A)$ or duplicate $(B)$ determinations. The two experiments were carried out with different lots of microplates.

Tybjaerg-Hansen et al. (9) observed that the mean plasma cholesterol in 10 FDB heterozygotes ( $3.69 \mathrm{~g} /$ liter) was similar to that of $\mathrm{FH}$ heterozygotes. However, in a study by Innerarity et al. (7) the mean cholesterol was $2.69 \mathrm{~g} /$ liter in FDB subjects in contrast to $3.60 \mathrm{~g} /$ liter in a large group of $\mathrm{FH}$ heterozygotes (7). Part of the controversy may arise from different screening strategies. Tybjaerg-Hansen et al. (9) included patients who had been diagnosed clinically as FH heterozygotes, whereas other investigators may have excluded such patients. In addition, the expression of the FDB mutation may be modulated by environmental and genetic factors. Hobbs et al. (27) provided evidence for the existence of a dominant gene attenuating the expression of familial hypercholesterolemia. Manke et al. (28) claimed that the apoE polymorphism influences LDL-C in familial defective apoB-100. Variable expression of the FDB mutation has been observed by Friedl et al. (29), who described a male carrier with normal plasma LDL, and by Myant et al. (30), who identified two normocholesterolemic heterozygotes. In this regard, it is worth to note that Y.B., the heterozygote daughter of our index patient, had normal LDL-C. Thus, the possibility that in the $\mathrm{B}$. family a LDL-lowering genetic factor exists that accounts for the surprisingly low LDL concentration in the homozygous patient (F.B.) cannot entirely be ruled out presently. While this manuscript was in preparation, another homozygous patient with FDB was reported (31). Her total cholesterol ranged between 2.99 and $3.31 \mathrm{~g} /$ liter, strongly suggesting that, in general, FDB causes less severe hypercholesterolemia than $\mathrm{FH}$.

This prompted us to investigate the interaction of FDBLDL with LDL receptors in human skin fibroblasts. In the past, the actual receptor binding activity of FDB-LDL was dif- 
ficult to determine because pure FDB-LDL had not been available. Early competition studies with LDL from heterozygotes resulted in $\sim 30 \%$ binding to LDL receptors compared with normal LDL (7). Using the mAb MB19, which binds to one of two common apoB alleles with 11-fold higher affinity than to the other, Innerarity et al. (8) partially purified FDB-LDL by affinity chromatography and estimated that it displayed only $3-5 \%$ of the normal binding activity.

In this study, binding, uptake, and degradation of FDBLDL from the homozygous patient was greatly diminished, but not completely abolished. The results of the direct binding and the competition studies indicate that the binding activity of FDB-LDL ( $1.019-1.063 \mathrm{~kg} /$ liter) is $\sim 20 \%$ of normal.

We ruled out that the residual receptor binding activity of FDB-LDL was due to an abnormally high apoE content. In the FDB homozygote and in healthy individuals, VLDL and IDL prepared by ultracentrifugation contained, on average, more than one molecule of apoE per molecule of apoB. This is in line with previous estimates (32-35). LDL and LDL subfractions from the FDB homozygote did not contain more apoE than normal. This also held true when the apoE distribution was studied by gel filtration.

In the homozygous patient there was a marked preponderance of LDL particles with densities $>1.037 \mathrm{~kg} /$ liter. We therefore hypothesized that FDB-LDL subfractions differed in their affinity for LDL receptors. Competition studies showed that the FDB mutation completely disrupted receptor binding in LDL-5 and LDL-6, the small and dense particles that were elevated in the plasma of the homozygous patient. A remarkable finding was that LDL-1 and LDL-2 were as effective as normal LDL in competing for the receptor binding of labeled LDL, whereas LDL-3 and LDL-4 displayed intermediate activity. These results are in line with the estimate that total FDBLDL (1.019-1.063 kg/liter) showed $\sim 20 \%$ receptor binding, which was most likely contributed by LDL-1 and LDL-2 particles. The data are also in perfect agreement with earlier observations. Comparing the receptor binding of LDL subfractions from FDB heterozygotes, Innerarity et al. (5) found that the functionally defective LDL accumulated in small dense LDL.

The relative apoE content in FDB-LDL subfractions was not elevated above normal, as discussed. Prima vista, this was circumstantial evidence against the possibility that apoE influenced the receptor binding of FDB-LDL subfractions. However, when we removed apoE-containing particles from LDL using immunoaffinity chromatography, the uptake of LDL-1 and LDL-2 by cultured cells was completely abolished. Interestingly, apoE removal did not diminish the residual receptor binding activity of LDL-3 and LDL-4.

The implications of these findings with regard to the structure of the apoB receptor binding domain are difficult to determine, since knowledge of its spatial organization in normal apoB is very limited. Current opinion predicates that lysine residues are involved in the interaction of $\mathrm{apoB}$ with five acidic cysteine-rich repeats of the LDL receptor molecule $(36,37)$. In LDL, chemically modifiable lysines exist in two types of microenvironments. In the first, they titrate like free lysines (i.e., with pK 10.5), suggesting that they do not interact strongly with other groups. In the second, they possess a pK value of 8.9. 10 of these $\mathrm{p} K 8.9$ lysines lie in the putative receptor binding domain of apoB-100 (residues 3000-3600) and are believed to participate in the binding of normal apoB-100 to LDL receptors (38). Substitution of glutamine for arginine at position
3500 induces conformational changes sufficient to redistribute seven lysine residues from the $\mathrm{p} K 8.9$ pool to the normally titrating pool (39). Arginine at position 3500 therefore appears to be important for maintaining the correct conformation of the adjacent receptor binding domain. Milne et al. (40) have examined the effects of $\mathrm{mAbs}$ on the receptor binding of LDL. They propose a model in which the basic amino acid residues involved in the binding of apoB to the LDL receptor are clustered in two short sequences extending from residues 3147 to 3157 and from residues 3359 to 3367 , respectively. The two stretches are held in proximity by folding of an interposed proline-rich cluster (40). According to our results, arginine at position 3500 is crucial to the receptor binding of LDL at the lower and upper limits of the density spectrum. In contrast, in LDL of intermediate density apoB appears to adopt a conformation allowing residual receptor binding despite the FDB mutation. These findings concur with the idea that in normal LDL an optimal distance between the two basic clusters exists, which is stabilized by arginine 3500, regardless of the surface curvature of the particle. In FDB the stabilizing effect of arginine 3500 is lost. The distance between the two basic clusters would then become related to the surface curvature. Thus, on large FDB-LDL the two positive clusters may be too far apart to fit into the binding domains of the LDL receptor, whereas on small FDB-LDL they may be too close together. Although speculative, this possibility is consistent with previous work. First, immunoelectron microscopy studies have shown that the distance between apoB epitopes on LDL can increase with the particle diameter (41). This suggests that apoB has some intrinsic flexibility on the LDL surface and that its conformation may be altered in response to changes of the curvature radius. Second, Nigon et al. (42) reported that, among LDL subfractions from healthy subjects, those with intermediate density have the highest affinities for LDL receptors. Third, there is abundant evidence that during the VLDL to LDL delipidation cascade apoB-100 undergoes profound conformational changes affecting its affinity for the $\operatorname{LDL}$ receptor $(43,44)$.

To throw additional light on the hypothesis that FDB-LDL subfractions differed by the conformation of apoB, we examined the binding of the mAb MB47 to LDL subfractions from the homozygote (F.B.). Previous work has shown that MB47 binds to FDB-LDL with higher affinity than to normal LDL (45). It was in good agreement with those studies that LDL (1.019-1.063 kg/liter) from both the homozygous patient and his heterozygous daughter had higher affinities for MB47 than normal LDL. When the binding of MB47 to LDL subfractions from the homozygote was investigated, marked differences were observed. Their magnitude was similar to the differences seen between LDL from normal subjects, FDB heterozygotes, and the FDB homozygote. Thus, the conformation of the MB47 epitope was clearly different between FDB-LDL subfractions. Precisely those subfractions with lowest receptor binding (LDL-5 and LDL-6) had the highest affinity to MB47. On the other hand, LDL-1 from the homozygote (F.B.) had the lowest affinity for MB47, indicating that there was no clear-cut inverse correlation between receptor binding activity and MB47 affinity. This is, however, not surprising if one considers that the MB47 epitope is located between amino acids 3441 and 3569 , and that these residues may not directly be involved in the interaction with the LDL receptor (2).

The present data provide novel insights into the molecular mechanisms causing the accumulation of small dense LDL in 
FDB. Innerarity et al. (5) speculated that in FDB small dense LDL are generated in the circulation during the prolonged halflife of LDL. Our data, however, suggest that two other processes lead to the selective preponderance of small dense LDL in FDB. First, by virtue of their apoE moiety buoyant FDBLDL (LDL-1 and LDL-2) are taken up regularly by LDL receptors and, therefore, do not circulate longer than normal. Second, the FDB mutation appears to distort the structure of the apoB receptor binding domain preferentially on particles at the extremes of the LDL density distribution (LDL-1, LDL-2, LDL-5, LDL-6 ), but to a lower degree on the LDL subfractions with intermediate density, i.e. LDL-3 and LDL-4. This is in good correspondence with a previous report showing that among LDL subfractions from normals, those with intermediate density have the highest affinities for LDL receptors (42).

According to current opinion (46), small dense LDL are derived from large, triglyceride-rich lipoproteins, whereas large LDL are believed to originate from small VLDL. Thus, hypercholesterolemia may remain moderate in FDB as long as VLDL production is normal and large apoE-containing LDL are produced that are taken up by hepatic LDL receptors. A more complex situation, however, may arise if the generation of VLDL and small dense LDL is enhanced as a consequence of additional metabolic disorders.

Accumulation of small dense LDL is not unique to familial defective apoB-100. Increased concentrations of small dense LDL usually occur in combination with low HDL and high triglycerides, the triad being referred to as the "atherogenic lipoprotein phenotype" $(47,48)$. It is related to familial combined hyperlipidemia, a frequent inherited disorder of lipoprotein metabolism with increased cardiovascular risk (49). The gene locus responsible for familial combined hyperlipidemia has not been identified so far. Although there is some evidence that familial combined hyperlipidemia is not linked to the apoB gene $(50,51)$, the present findings raise the possibility that some forms of dyslipoproteinemia exist in which small dense LDL are elevated due to mutations in apoB other than the glutamine for arginine substitution in position 3500 .

In the cell culture experiments, we showed that the relatively mild hypercholesterolemia in homozygous FDB results from impaired clearance of some, but not all, LDL subfractions. However, an additional compensatory mechanism involving the expression of hepatic LDL receptors might be active. In healthy subjects, cholesterol is targeted to the liver by apoE and apoB. In familial type III hyperlipoproteinemia, defective binding of apoE to LDL receptors diminishes remnant clearance. This results in depleted hepatic cholesterol pools and upregulated LDL receptors. Ultimately, LDL catabolism is enhanced in type III hyperlipoproteinemia, and LDL-C decreases (52). In FDB, cholesterol delivery to the liver is impaired because apoB-100 is defective. The resulting upregulation of hepatic LDL receptors may enhance remnant clearance (via apoE). Since remnants taken up into the liver do not enter the LDL pool, LDL generation rates in FDB may be lower than in $\mathrm{FH}$, additionally contributing to the relatively mild hypercholesterolemia in FDB. There are several lines of evidence that support this concept. First, IDL-C and apoE were normal in our patient and in his heterozygous relatives, whereas both are elevated in $\mathrm{FH}$ (53). Second, our experience with pravastatin in the FDB homozygote along with observations by others ( 31 , 54 ) show that stimulation of LDL receptors with 3-hydroxy-3methylglutaryl-coenzyme A reductase inhibitors lowers LDL in FDB, probably by enhancing the removal of apoE-containing LDL precursors from the circulation. This, however, remains to be proven by in vivo kinetic studies.

Interestingly, neither our homozygous patient (F.B.) nor his heterozygous brother (W.B.) showed any clinical evidence for atherosclerosis. At present, the impact of FDB on atherogenesis is still an open question. In the study by Tybjaerg-Hansen et al. (9), 7 of 10 FDB subjects were reported to have coronary heart disease. Geisel et al. ( 55) observed atherosclerosis only in those FDB patients displaying the highest cholesterol levels. Rauh et al. (56) analyzed echocardiographic changes in 31 FDB heterozygotes and 45 normolipidemic controls. In $67.7 \%$ of the FDB heterozygotes they observed atherosclerotic plaques in the aortic root, compared with $3.2 \%$ in age-matched controls. Moreover, in the FDB group, the aortic valve was affected in $22.6 \%$, whereas there was no valvular involvement in the control group. These data suggest that FDB heterozygotes exhibit premature atherosclerosis. However, the question whether the atherogenic effect of hypercholesterolemia due to FDB differs from that caused by defective LDL receptors cannot be answered at present.

In summary, we have identified a homozygous patient with FDB. In this patient, hypercholesterolemia was less severe than in homozygous familial hypercholesterolemia and in many FDB heterozygotes. Two compensatory mechanisms seem to be responsible for this. First, the receptor-mediated catabolism of buoyant FDB-LDL is obviously normal in FDB due to the association of apoE with these particles. Second, in LDL subfractions of intermediate density, apoB-100 itself displays some residual receptor binding activity. Future investigations will have to prove that additional compensatory mechanisms are active in FDB, such as an enhanced influx of remnant lipoproteins into the liver via functional apoE. The identification of this homozygote patient will greatly facilitate these studies and open up unprecedented opportunities to obtain further insights into the pathobiochemistry of FDB. In addition, unresolved questions concerning the roles of apoB, apoE, and the LDL receptor in lipoprotein metabolism and atherosclerosis can be addressed.

\section{Acknowledgments}

We thank Sabine Cezanne, Bettina Donnerhak, and Ulrike Stein for technical assistance. Angela Beckmann and Rüdiger Siekmeier helped with the cell culture experiments. We are indebted to Dr. Brian J. McCarthy (The Gladstone Foundation Laboratories for Cardiovascular Disease, San Francisco, CA) for providing a reference DNA sample from a patient with heterozygous familial defective apoB-100, to Dr. Linda K. Curtiss (Research Institute of Scripps Clinic, La Jolla, CA) for supplying antibody MB47, and to Prof. Dr. Gert M. Kostner (Institute of Medical Biochemistry, Graz) for supplying polyclonal antibody specific for apolipoprotein E. Drs. Nicholas B. Myant (MRC Lipoprotein Team, Hammersmith Hospital, London ) and Barry G. Woodcock (Department of Clinical Pharmacology, University Hospital, Frankfurt) contributed many helpful suggestions. This article is dedicated to Prof. Dr. Martin Kaltenbach on the occasion of his 65th birthday.

\section{References}

1. Myant, N. B. 1990. Cholesterol metabolism, LDL, and the LDL receptor. Academic Press, New York. 112-183.

2. Young, S. G. 1990. Recent progress in understanding apolipoprotein B. Circulation. 82:1574-1594. 
3. Scott, J. 1989. The molecular and cell biology of apolipoprotein B. Mol. Biol. Med. 6:65-80.

4. Goldstein, J. L., and M. S. Brown. 1989. Familial hypercholesterolemia. In The Metabolic Basis of Inherited Disease. 6th ed. Vol. I. C. R. Scriver, A. L. Beaudet, W. S. Sly, and D. Valle, editors. McGraw-Hill Inc., New York. 12151250.

5. Innerarity, T. L., K. H. Weisgraber, K. S. Arnold, R. W. Mahley, R. M. Krauss, G. L. Vega, and S. M. Grundy. 1987. Familial defective apolipoprotein B-100: low density lipoproteins with abnormal receptor binding. Proc. Natl. Acad. Sci. USA. 84:6919-6923.

6. Soria, L. F., E. H. Ludwig, H. R. G. Clarke, G. L. Vega, S. M. Grundy, and B. J. McCarthy. 1989. Association between a specific apolipoprotein B mutation and familial defective apolipoprotein B-100. Proc. Natl. Acad. Sci. USA. 86:587591.

7. Innerarity, T. L., R. W. Mahley, K. H. Weisgraber, T. P. Bersot, R. M. Krauss, G. L. Vega, S. M. Grundy, W. Friedl, J. Davignon, and B. J. McCarthy. 1990. Familial defective apolipoprotein B-100: a mutation of apolipoprotein B that causes hypercholesterolemia. J. Lipid Res. 31:1337-1349.

8. Innerarity, T. L., M. E. Balestra, K. S. Arnold, R. W. Mahley, G. L. Vega, S. M. Grundy, and S. G. Young. 1988. Isolation of defective receptor-binding low density lipoproteins from subjects with familial defective apolipoprotein B-100. Arteriosclerosis. 8:551a. (Abstr.)

9. Tybjaerg-Hansen, A. J., J. Gallagher, J. Vincent, P. Houlsten, P. Talmud, A. M. Dunning, M. Seed, A. Hamsten, S. E. Humphries, and N. B. Myant. 1990. Familial defective apolipoprotein B-100: Detection in the United Kingdom and Scandinavia, and clinical characteristics of ten cases. Atherosclerosis. 80:235242.

10. März, W., V. Ruzicka, T. Pohl, K. H. Usadel, and W. Groß. 1992. Familial defective apolipoprotein B-100: mild hypercholesterolemia without atherosclerosis in a homozygous patient. Lancet. 340:1362.

11. Ruzicka, V., W. März, A. Russ, and W. Groß. 1992. Apolipoprotein B (Arg ${ }^{3500} \rightarrow$ Gln) allele specific PCR. Large scale screening of pooled blood samples. J. Lipid Res. 33:1563-1567.

12. Hansen, P. S., N. Rüdiger, A. Tybjaerg-Hansen, O. Faergeman, and N. Gregersen. 1991. Detection of the apoB-3500 mutation (glutamine for arginine) by gene amplification and cleavage with MspI. J. Lipid Res. 32:1229-1233.

13. Law, S. W., S. M. Grant, K. Higuchi, A. Hospattankar, K. Lackner, N. Lee, H. B. Brewer. 1986. Human liver apolipoprotein B-100 cDNA: complete nucleic acid and derived amino acid sequence. Proc. Natl. Acad. Sci. USA. 83:8142-8146.

14. Sanger, F., S. Nicklen, and A. R. Coulson. 1977. A new method for sequencing DNA. Proc. Natl. Acad. Sci. USA. 74:5463-5467.

15. März W., and W. Gro $\beta$. 1986. Analysis of plasma lipoproteins by ultracentrifugation in a new fixed angle rotor: evaluation of a phosphotungstic acid/ $\mathrm{MgCl}_{2}$ precipitation and a quantitative lipoprotein electrophoresis assay. Clin. Chim. Acta. 160:1-18.

16. Lindgren, F. T. 1975. Preparative ultracentrifuge laboratory procedures and suggestions for lipoprotein analysis. In Analysis of Lipids and Lipoproteins. E. G. Perkins, editor. American Oil Chemists' Society, Champaign, IL. 204-224.

17. März, W., S. Cezanne, and W. Gro $\beta$. 1991. Immunoblotting of apolipoprotein $\mathrm{E}$ in immobilized pH gradients. Electrophoresis. 12:59-63.

18. Rall, S. C., K. H. Weisgraber, and R. W. Mahley. 1986. Plasma lipoproteins. Part A. Isolation and characterization of apolipoprotein E. Preparation, structure, and molecular biology. Methods Enzymol. 128:273-287.

19. Baumstark, M. W., W. Kreutz, A. Berg, I. Frey, and J. Keul. 1990. Structure of human low-density lipoprotein subfractions, determined by X-ray smallangle scattering. Biochim. Biophys. Acta. 1037:48-57.

20. März, W., R. Siekmeier, H. Scharnagl, U. B. Seiffert, and W. Groß. 1992. Fast Lipoprotein Chromatography (FLPC): a new method for plasma lipoprotein analysis. Clin. Chem. In press.

21. Goldstein, J. L., S. K. Basu, and M. S. Brown. 1983. Biomembranes. Part L. Membrane biogenesis. Receptor-mediated endocytosis of low-density lipoprotein in cultured cells. Methods Enzymol. 98:241-260.

22. Sinn, H. J., H. H. Schrenk, E. A. Friedrich, D. P. Via, and H. A. Dresel. 1988. Radioiodination of proteins and lipoproteins using n-bromosuccinimide as oxidizing reagent. Anal. Biochem. 170:186-192.

23. Gibson, J. C., A. Rubinstein, P. R. Bukberg, and W. V. Brown. 1983. Apolipoprotein E-enriched lipoprotein subclasses in normolipidemic subjects. $J$. Lipid Res. 24:886-898.

24. Blum, C. B., L. Aron, and R. Sciacca. 1980. Radioimmunoassay studies of human apolipoprotein E. J. Clin. Invest. 66:1240-1250.

25. Fainaru, M., R. J. Havel, and K. Imaizumi. 1977. Radioimmunoassay of arginine-rich apolipoprotein of rat serum. Biochim. Biophys. Acta 490:144-155.

26. Castro, G., and C. J. Fielding. 1984. Evidence for the distribution of apolipoprotein $\mathrm{E}$ between lipoprotein classes in human normocholesterolemic plasma and for the origin of unassociated apolipoprotein $\mathrm{E}(\mathrm{LpE})$. J. Lipid Res. 25:58-67.

27. Hobbs, H. H., E. Leitersdorf, C. C. Leffert, D. R. Cryer, M. S. Brown, and J. L. Goldstein. 1989. Evidence for a dominant gene that suppresses hypercholes- terolemia in a family with defective low density lipoprotein receptors. J. Clin. Invest. 84:656-664.

28. Manke, C., H. Schuster, C. Keller, G. Wolfram, and N. Zöllner. 1992. Influence of the apolipoprotein $\mathrm{E}$ polymorphism on the lipid profile in patients with familial defective apolipoprotein B-100. Klin. Wochenschr. 69(Suppl. 28): 73. (Abstr.)

29. Friedl, W., E. H. Ludwig, M. E. Balestra, K. S. Arnold, B. Paulweber, F. Sandhofer, B. J. McCarthy, and T. L. Innerarity. 1991. Apolipoprotein B gene mutations in Austrian subjects with heart disease and their kindred. Arterioscler. Thromb. 11:371-378.

30. Myant, N. B., J. J. Gallagher, B. L. Knight, S. N. McCarthy, J. Frostegard, J. Nilsson, A. Hamsten, P. Talmud, and S. E. Humphries. 1991. Clinical signs of familial hypercholesterolemia in patients with familial defective apolipoprotein B-100 and normal low density lipoprotein receptor function. Arterioscler. Thromb. 11:691-703.

31. Funke, H., S. Rust, U. Seedorf, B. Brennhausen, A. Chirazi, C. Motti, and G. Assmann. 1992. Homozygosity for familial defective apolipoprotein B-100 (FDB) is associated with lower plasma cholesterol concentrations than homozygosity for familial hypercholesterolemia (FH). Circulation. 86(Suppl. I): I-691. (Abstr.)

32. Eisenberg, S., G. Friedman, and T. Vogel. 1988. Enhanced metabolism of normolipidemic human plasma very low density lipoprotein in cultured cells by exogenous apolipoprotein E-3. Arteriosclerosis. 8:480-487.

33. Friedman, G., D. Gavish, T. Vogel, and S. Eisenberg. 1990. Cellular metabolism of human plasma intermediate-density lipoprotein (IDL). Biochim. Biophys. Acta. 104:118-126.

34. Havel, R. J., N. Yamada, and D. M. Shames. 1987. Role of apolipoprotein $\mathrm{E}$ in lipoprotein metabolism. Am. Heart J. 113:470-474.

35. Gianturco, S. H., A. M. Gotto, S.-L. C. Hwang, J. B. Karlin, A. H. Y. Lin, S. C. Prasad, and W. A. Bradley. 1983. Apolipoprotein E mediates uptake of Sf 100-400 hypertriglyceridemic very low density lipoproteins by the low density lipoprotein receptor pathway in normal human fibroblasts. J. Biol. Chem. 258:4526-4533.

36. Weisgraber, K. H., T. L. Innerarity, and R. W. Mahley. 1978. Role of the lysine residues of plasma lipoproteins in high affinity binding to cell surface receptors on human fibroblasts. J. Biol. Chem. 253:9053-9062.

37. Russell, D. W., M. S. Brown, and J. L. Goldstein. 1989. Different combinations of cysteine-rich repeats mediate binding of low density lipoprotein receptor to two different proteins. J. Biol. Chem. 264:21682-21688.

38. Lund-Katz, S., J. A. Ibdah, J. Y. Letizia, M. T. Thomas, and M. C Phillips. 1988. $\mathrm{A}^{13} \mathrm{C}$ NMR characterization of lysine residues in apolipoprotein $\mathrm{B}$ and their role in binding to the low density lipoprotein receptor. J. Biol. Chem. 263:13831-13838.

39. Lund-Katz, S., T. L. Innerarity, K. S. Arnold, L. K. Curtiss, and M. C. Philips. 1991. $C^{13}$ NMR evidence that substitution of glutamine for arginine 3500 in familial defective apoB-100 disrupts the conformation of the receptor binding domain. J. Biol. Chem. 266:2701-2704.

40. Milne, R., R. Théolis, R. Maurice, R. J. Pease, P. K. Weech, E. Rassart J.-C. Fruchart, J. Scott, and Y. L. Marcel. 1989. The use of monoclonal antibodies to localize the low density lipoprotein receptor-binding domain of apolipoprotein B. J. Biol. Chem. 264:19754-19760.

41. Chatterton, J. E., M. L. Phillips, L. K. Curtiss, R. W. Milne, Y. L. Marcel, and V. N. Schumaker. 1991. Mapping apolipoprotein B on the low density lipoprotein surface by immunoelectron microscopy. J. Biol. Chem. 266:5955-5962.

42. Nigon, F., P. Lesnik, M. Rouis, and M. J. Chapman. 1991. Discrete subspecies of human low density lipoproteins are heterogeneous in their interaction with the cellular LDL receptor. J. Lipid Res. 32:1741-1753.

43. Schonfeld, G., W. Patsch, B. Pfleger, J. L. Witztum, and S. W. Weidman 1979. Lipolysis produces changes in the immunoreactivity and cell reactivity of very low density lipoproteins. J. Clin. Invest. 64:1288-1297.

44. Krul, E. S., M. J. Tikkanen, T. G. Cole, J. M. Davie, and G. Schonfeld 1985. Roles of apolipoproteins $B$ and $E$ in the cellular binding of very low density lipoproteins. J. Clin. Invest. 76:361-369.

45. Weisgraber, K. H., T. L. Innerarity, Y. M. Newhouse, S. G. Young, K. S Arnold, R. M. Krauss, G. L. Vega, S. M. Grundy, and R. W. Mahley. 1988 Familial defective apolipoprotein B-100: enhanced binding of monoclonal antibody MB47 to abnormal low density lipoproteins. Proc. Natl. Acad. Sci. USA 85:9758-9762.

46. Krauss, R. M. 1987. Relationship of intermediate and low-density lipoprotein subspecies to risk of coronary artery disease. Am. Heart J. 113:578-582.

47. Austin, M. A., M.-C. King, K. M. Vranizan, and R. M. Krauss. 1990 Atherogenic lipoprotein phenotype. A proposed genetic marker for coronary heart disease. Circulation. 82:495-506.

48. Nishina, P. M., J. P. Johnson, J. K. Naggert, and R. M. Krauss. 1992. Linkage of atherogenic lipoprotein phenotype to the low density lipoprotein re ceptor locus on the short arm of chromosome 19. Proc Natl Acad Sci. USA. 89:708-712.

49. Goldstein, J. L., H. G. Schrott, W. R. Hazzard, E. L. Bierman, A. G. Motulsky. 1973. Hyperlipidemia in coronary heart disease. II. Genetic analysis of 
lipid levels in 176 families and delineation of a new inherited disorder, combined hyperlipidemia. J. Clin. Invest. 52:1544-1568.

50. Rauh, G., H. Schuster, B. Müller, S. Schewe, C. Keller, G. Wolfram, and N. Zöllner. 1990. Genetic evidence from 7 families that the apolipoprotein B genc is not involved in familial combined hyperlipoproteinemia. Atherosclerosis. 83:81-87.

51. Wojciechowski, A. P., M. Farrall, P. Cullen, T. M. E. Wilson, J. D. Bayliss, B. Farren, B. A. Griffin, M. J. Caslake, C. J. Packard, J. Shepherd, R. Thakker, and J. Scott. 1991. Familial combined hyperlipidemia linked to the apolipoprotein AI-CIII-AIV gene cluster on chromosome 11q23-q24. Nature (Lond.). 349:161-164.

52. Mahley, R. W., and S. C. Rall. 1989. Type III hyperlipoproteinemia (dysbetalipoproteinemia). The role of apolipoprotein $\mathrm{E}$ in normal and abnormal lipoprotein metabolism. In The Metabolic Basis of Inherited Disease. 6th ed. Vol. I. C. R. Scriver, A. L. Beaudet, W. S. Sly, and D. Valle, editors. McGraw Hill Inc., New York. 1195-1213.

53. Soutar, A. K., N. B. Myant, and G. R. Thompson. 1982. The metabolism of very-low-density and intermediate density lipoproteins in patients with familial hypercholesterolemia. Atherosclerosis. 43:217-231.

54. Maher, V. M. G., J. J. Gallagher, G. R. Thompson, and N. B. Myant. 1991. Response to cholesterol lowering drugs in familial defective apolipoprotein B-100. Atherosclerosis. 91:73-76.

55. Geisel, J., T. Schleifenbaum, B. Wei $\beta$ haar, and K. Oette. 1992. Screening for familial defective ApoB-100 in newborns. 59th Congress of the European Atherosclerosis Society, Nice. 54. (Abstr.)

56. Rauh, G., C. H. Wagner, H. Keller, G. Schuster, G. Wolfram, and N. Zöllner. 1992. Echocardiographic changes in 31 patients with familial defective apolipoprotein B-100. 59th Congress of the European Atherosclerosis Society, Nice. 115. (Abstr.)

57. März, W., R. Siekmeier, W. Groß, and G. M. Kostner. 1993. Determination of lipoprotein (a): a comparison of three methods. Eur. J. Clin. Chem. Clin. Biochem. 31:295-301.

58. Friedewald, W. T., R. I. Levy, and D. S. Fredrickson. 1972. Estimation of the concentration of low-density lipoprotein cholesterol in plasma, without use of the preparative ultracentrifuge. Clin. Chem. 18:499-502. 